\title{
Home blood glucose concentrations in maturity-onset diabetes
}

\author{
R B PAISEY，P BRADSHAW， M HARTOG
}

\section{Summary and conclusions}

Blood glucose concentrations during normal daily activities were measured in 106 patients with maturityonset diabetes from capillary blood samples collected on to filter paper. Samples were taken before and two hours after main meals, before going to bed, and, in 51 cases, during the night. Fasting and mid-morning values were closely correlated with the mean values over 24 hours irrespective of the type of anti-diabetic treatment being given. Postprandial blood glucose concentrations remained below $11.5 \mathrm{mmol} / 1(207 \mathrm{mg} / 100 \mathrm{ml})$ when the fasting blood glucose value was $7 \cdot 0 \mathrm{mmol} / 1(126 \mathrm{mg} / 100 \mathrm{ml})$ or less, and repeated fasting blood glucose values exceeding $7.0 \mathrm{mmol} / 1$ were associated with raised blood glycosylated haemoglobin concentrations.

Diabetic control in maturity-onset diabetes may be satisfactorily monitored by regular measurement of fasting or mid-morning blood glucose values.

\section{Introduction}

A relation between the quality of diabetic control, as assessed by blood glucose measurements, and the development of diabetic complications is now widely accepted. ${ }^{1}$ Hence there is a need for accurate and cheap methods of monitoring diabetic control. We have measured glucose concentrations in capillary blood samples collected at home on to filter paper strips by patients with maturity-onset diabetes. Blood was collected serially over 24 hours, and our aim was to investigate in each case the relation between individual blood glucose values and the mean of all values over the 24 hours.

\section{Patients and methods}

One hundred and six patients with maturity-onset diabetes (age range 40-79 years) participated in the study. Thirty-six were being treated with diet alone, while the others were also taking an oral hypoglycaemic agent-namely, metformin (18 patients), chlorpropamide (15), glibenclamide twice daily (23), and glipizide thrice daily (14). They were asked to collect capillary blood samples on to a filter paper strip ${ }^{2}$ during a normal working day $(a)$ before each of the three main meals, $(b)$ two hours after each main meal, $(c)$ before going to bed, and $(d)$ in the night if woken. Most were given an Autolet, and all were shown the technique of collecting capillary blood when recruited into the study. Forty patients who completed three or more collections over four to eight weeks had their blood glycosylated haemoglobin concentrations measured at the end of the study.

Measurement of capillary blood glucose concentrations-Only filter paper strips with at least seven large enough blood spots were accepted for analysis. Glucose was eluted with $2.5 \%$ sulphosalicylic acid from $6 \mathrm{~mm}$ diameter discs punched from the centre of each blood spot and measured by autoanalyser, the dialysis stage being bypassed. ${ }^{3}$ The coefficient of variation of the method is $4 \%$.

Royal Infirmary, Bristol BS2 8HW

R B PAISEY, MRCP, lecturer, university department of medicine P BRADSHAW, FIMLS, chief technician, department of chemical pathology M HARTOG, FRCP, reader, university department of medicine
Blood glycosylated haemoglobin concentrations were measured as the percentage of $\mathrm{HbA}_{1}$ by a commercially available column chromatographic technique (Quik-sep). ${ }^{4}$ Blood $(5 \mathrm{ml}$ ) was taken into glass Sequestrene tubes, stored at $4^{\circ} \mathrm{C}$, and examined within one week. In our laboratory the coefficient of variation of the method is $4.5 \%$, and the normal range is $6-8 \%$.

\section{Results}

Figure 1 shows for all patients the correlation between the fasting blood glucose concentrations and the mean of all blood glucose values over the 24 hours. Five patients who completed at least 10 collections showed a consistent relation between the fasting concentration and mean 24-hour blood glucose value (fig 2). Figure 3 gives the results

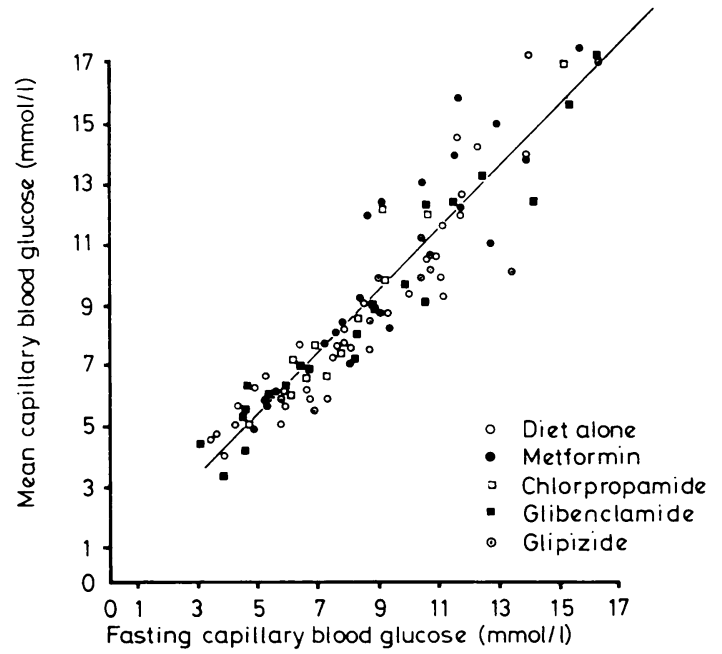

FIG 1 -Correlation between fasting blood glucose concentrations and mean of all blood glucose values over 24 hours. $(\mathrm{n}=106 . \mathrm{r}=0.93$.

Conversion: $S I$ to traditional units-Blood glucose: $1 \mathrm{mmol} / \mathrm{l} \approx 18 \mathrm{mg} / 100 \mathrm{ml}$

in 79 collections in which the fasting blood glucose concentration was below $10 \mathrm{mmol} / 1(180 \mathrm{mg} / 100 \mathrm{ml})$ together with $95 \%$ confidence limits of mean capillary blood glucose values for a fasting value of $7 \mathrm{mmol} / 1$ $(126 \mathrm{mg} / 100 \mathrm{ml})$. In addition, no patient with a fasting capillary blood glucose concentration below $7 \mathrm{mmol} / 1$ had any postprandial capillary blood glucose value exceeding $11.5 \mathrm{mmol} / 1(207 \mathrm{mg} / 100 \mathrm{ml})$ during that day.

The table shows the correlation coefficients between capillary blood glucose concentrations at other times of day and the mean 24-hour value; high levels of significance were found, especially for concentrations two hours after breakfast and before lunch. Comparing the slopes of the correlations between fasting and mean 24-hour values in the different treatment groups showed no significant difference (fig 4), and in each group the fasting capillary blood glucose concentration, as compared with concentrations at other times, showed the best correlation with the mean 24-hour value.

There was good correlation between the mean of at least three fasting capillary blood glucose measurements taken over four to eight weeks and the percentage of $\mathrm{HbA}_{1}$ at the end of this time (fig 5). The percentage of $\mathrm{HbA}_{1}$ exceeded the upper limit of normal only when the mean fasting capillary blood glucose concentration exceeded $7 \mathrm{mmol} / 1$ (126 mg/100 ml). 


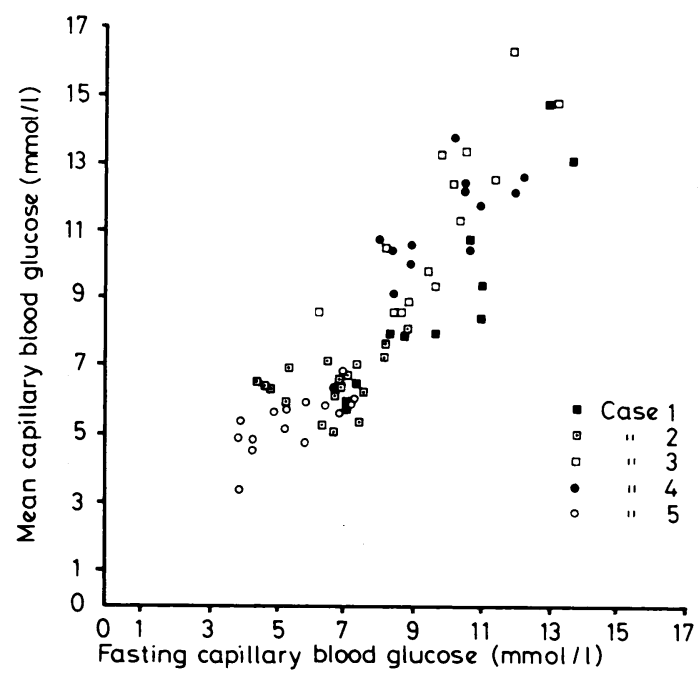

FIG 2-Relation between fasting capillary blood glucose concentrations and mean of all blood glucose values over 24 hours in five patients who completed 10 or more series of collections. (Blood glucose: $1 \mathrm{mmol} / 1 \approx 18 \mathrm{mg} / 100 \mathrm{ml}$.)

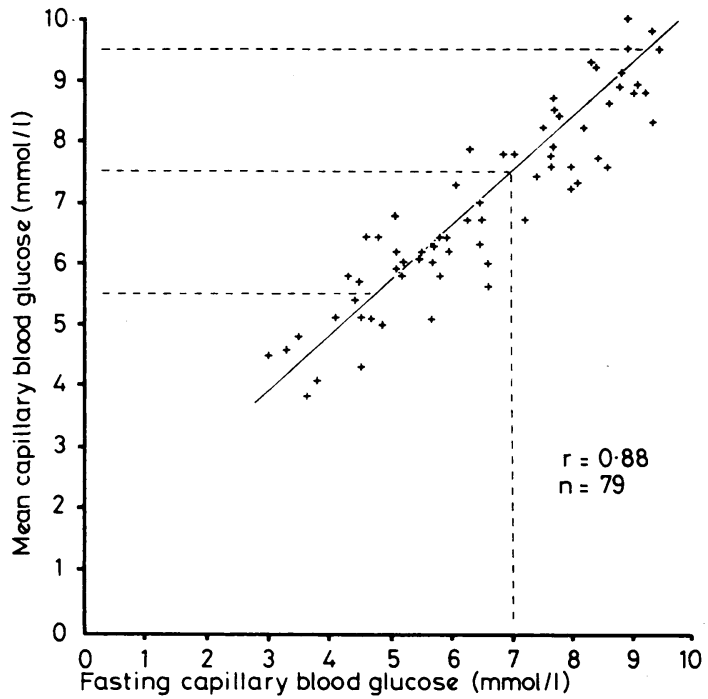

FIG 3-Correlation between fasting and mean blood glucose concentrations in 79 patients whose mean fasting blood glucose concentration was $<10 \mathrm{mmol} / 1(<180 \mathrm{mg} / 100 \mathrm{ml})$, with $95 \%$ confidence limits of mean blood glucose concentrations for fasting value of $7 \mathrm{mmol} / 1(126 \mathrm{mg} / 100 \mathrm{ml})$. (Blood glucose: $1 \mathrm{mmol} / 1 \approx 18 \mathrm{mg} / 100 \mathrm{ml}$.)

\section{Discussion}

These results confirm the clinical impression that blood glucose concentrations remain stable in maturity-onset diabetes and support the conclusion ${ }^{5}$ that the fasting blood glucose value accurately predicts the mean blood glucose concentrations during the rest of the 24 hours. Blood glucose control in maturityonset diabetes may thus be satisfactorily assessed from the mean of repeated measurements of the fasting blood glucose concentration. Samples at other times could also be used, particularly mid-morning, though the correlation with the mean blood glucose concentration might be less satisfactory in some patients because of the influence on blood glucose concentrations of dietary fibre, gastric emptying, and differing energy content of meals.

Cross-sectional studies of results of glucose tolerance tests in maturity-onset diabetes show a threshold of glucose intolerance beyond which microangiopathy becomes much more likely. ${ }^{6}$ ?
This threshold for the fasting blood glucose concentration is apparently between 6 and $7 \mathrm{mmol} / 1$ (108 and $126 \mathrm{mg} / 100 \mathrm{ml}$ ), and two hours after a $50-\mathrm{g}$ oral glucose load is between 12 and 13 $\mathrm{mmol} / \mathrm{l}(216$ and $234 \mathrm{mg} / 100 \mathrm{ml}$ ). Interestingly, therefore, in our series postprandial blood glucose concentrations never exceeded $11.5 \mathrm{mmol} / 1(207 \mathrm{mg} / 100 \mathrm{ml})$ when the fasting value had been $7 \mathrm{mmol} / 1(126 \mathrm{mg} / 100 \mathrm{ml})$ or less. Nevertheless, an increased risk of large-vessel disease occurs even in the mildest forms of glucose intolerance, ${ }^{8}$ and some workers suggest that treatment of maturity-onset diabetes should be adjusted to reduce fasting blood glucose concentrations to $6 \mathrm{mmol} / 1(108 \mathrm{mg} / 100 \mathrm{ml})$ or less.

Our results also show that the percentage of $\mathrm{HbA}_{1}$ correlates well with mean fasting blood glucose values, which agrees with the findings of Graf et al. ${ }^{9}$ Furthermore, the percentage of

Correlation coefficients for timed $v$ mean capillary blood glucose concentrations during 24 hours

\begin{tabular}{|c|c|c|c|c|c|c|c|c|}
\hline & Fasting & 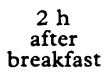 & $\begin{array}{l}\text { Before } \\
\text { lunch }\end{array}$ & $\begin{array}{c}2 \mathrm{~h} \\
\text { after } \\
\text { lunch }\end{array}$ & $\begin{array}{l}\text { Before } \\
\text { dinner }\end{array}$ & $\begin{array}{c}2 \mathrm{~h} \\
\text { after } \\
\text { dinner }\end{array}$ & $\begin{array}{c}\text { Before } \\
\text { going } \\
\text { to bed }\end{array}$ & $\begin{array}{c}\text { During } \\
\text { night }\end{array}$ \\
\hline $\begin{array}{l}\mathbf{r} \\
\mathbf{n}\end{array}$ & $\begin{array}{l}0.93 \\
106\end{array}$ & $\begin{array}{l}0.90 \\
102\end{array}$ & $\begin{array}{l}0.89 \\
106\end{array}$ & $\begin{array}{l}0.85 \\
104\end{array}$ & $\begin{array}{l}0.86 \\
105\end{array}$ & $\begin{array}{l}0.84 \\
103\end{array}$ & $\begin{array}{c}0 \cdot 87 \\
95\end{array}$ & $\begin{array}{c}0.81 \\
51\end{array}$ \\
\hline
\end{tabular}

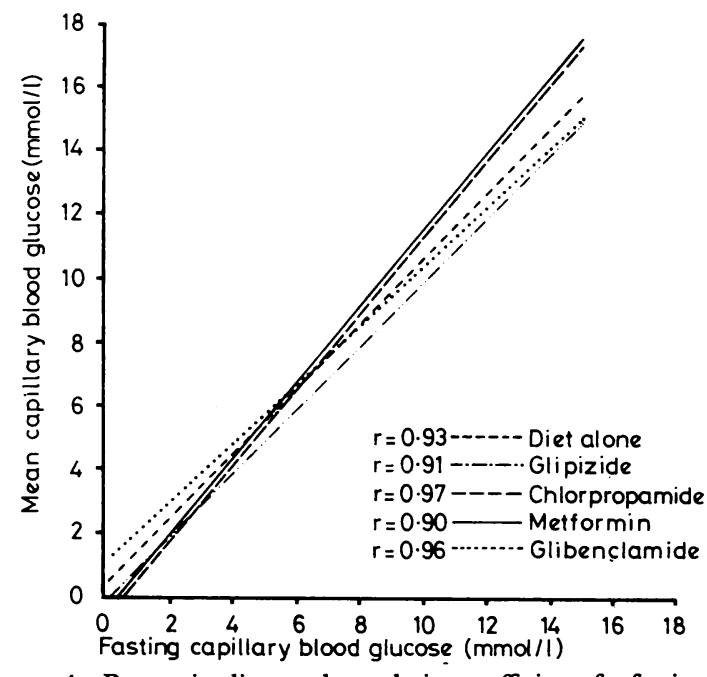

FIG 4-Regression lines and correlation coefficients for fasting $v$ mean blood glucose concentrations in different treatment groups. (Blood glucose: $1 \mathrm{mmol} / 1 \approx 18 \mathrm{mg} / 100 \mathrm{ml}$.)

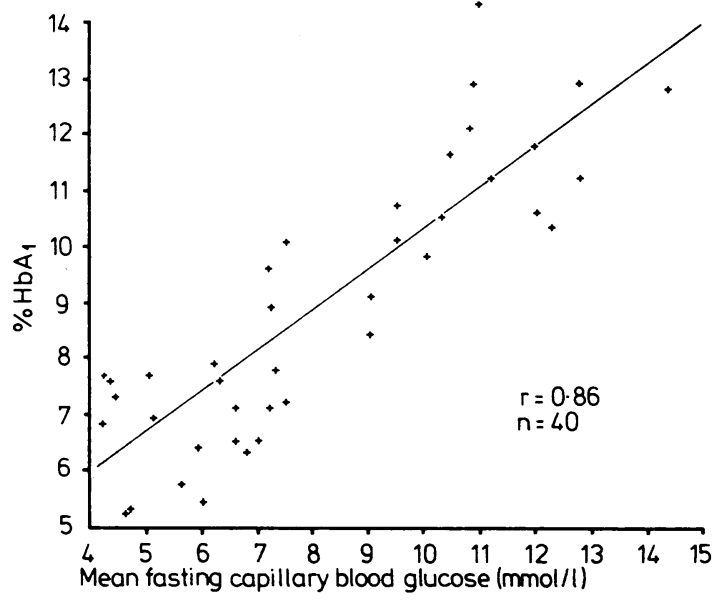

FIG 5-Correlation between mean of three or more fasting capillary blood glucose measurements and $\% \mathrm{HbA}_{1}$. (Blood glucose : $1 \mathrm{mmol} / 1 \approx 18 \mathrm{mg} / 100 \mathrm{ml}$.) 
$\mathrm{HbA}_{1}$ was above the upper limit of normal only in patients who had repeated fasting blood glucose values exceeding $7 \mathrm{mmol} / \mathrm{l}$.

Lastly, only 37 of the 106 patients studied had fasting blood glucose values below $7 \mathrm{mmol} / 1$; some were up to $16 \mathrm{mmol} / 1$ $(288 \mathrm{mg} / 100 \mathrm{ml})$.

We thank Dr D R Coles for allowing us to study patients under his care; Mr D White and Mrs G Barron for technical work; Drs A Hughes and C Roberts for statistical advice; and Miss Anne Brown and Mrs Zina Fear for typing the manuscript.

\section{References}

1 Jarrett RJ, Keen H. Hyperglycaemia and diabetes mellitus. Lancet 1976 ;ii:1009.

2 Wakelin K, Goldie DJ, Hartog M, Robinson AP. Measurement of capillary blood glucose in filter paper spots : an aid to the assessment of diabetic control. $\mathrm{Br}$ Med $\mathcal{F} 1978$;ii :468-9.
${ }^{3}$ West P, Marsland IG, Bradshaw P. Automated capillary blood spot glucose estimation. Med Lab Sci 1979;36:379-80.

4 Welch SG, Boucher BJ. A rapid micro-scale method for the measurement of haemoglobin Al $(a+b+c)$. Diabetologia 1978;14:209-11.

${ }^{5}$ Holman RR, Turner RC. The quest for basal normoglycaemia. Lancet $1977 ; \mathrm{i}: 469$.

${ }^{6}$ Dorf A, Ballentine EJ, Bennett PH. Retinopathy in Pima Indians. Relationships to glucose level, duration of diabetes, age at diagnosis of diabetes, and age at examination in a population with a high prevalence of diabetes mellitus. Diabetes 1976;25:554-60.

${ }^{7}$ Keen H, Jarrett RJ, Chlouverakis C, et al. The effect of treatment of moderate hyperglycaemia on the incidence of arterial disease. Postgrad Med F 1968;44:960-5.

${ }^{8}$ Reid DP, Hamilton PJS, Keen H, Brett GZ, Jarrett RJ, Rose G. Cardiorespiratory disease and diabetes among middle-aged male civil servants. Lancet $1974 ; \mathrm{i}: 469$.

${ }^{9}$ Graf RJ, Halter JB, Porte D. Glycosylated haemoglobin in normal subjects and subjects with maturity onset diabetes: evidence for a saturable system in man. Diabetes $1978 ; 27: 834-9$.

(Accepted 28 November 1979)

\section{Summary and conclusions}

One hundred and sixty ex-servicemen who had been prisoners of war in south-east Asia during 1942-5 were investigated for infection with Strongyloides stercoralis. Larvae were found in $44(27.5 \%)$ of the men, who had therefore been infected for 34-37 years. Direct microscopy of the faeces was the most successful diagnostic method, giving a positive result in 37 cases (84\%); multiple examinations were often necessary. Faecal culture was positive in 30 cases (68\%), but examination of duodenal fluid obtained with the string test gave a positive result in only $17(39 \%)$. The mean blood eosinophil count and mean serum IgE concentration were higher in the infected men, though normal values were often found in individual cases. Clinical manifestations of isolated strongyloides infection were analysed by comparing the infected men with control groups of ex-prisoners in south-east Asia without proved strongyloidiasis and exprisoners in Europe. Twenty-nine infected men (66\%) complained of non-specific urticaria, and $13(30 \%)$ had pathognomonic larva currens. Gastrointestinal symptoms significantly more common in the infected group were diarrhoea, indigestion, lower abdominal pain, pruritus ani, and weight loss $(p<0.05-p<0.0005)$.

The study group was thought to be reasonably representative of Allied ex-servicemen imprisoned in southeast Asia during the second world war. Probably there are many thousands of infected persons in several countries. The worm has an unusual ability to multiply, and larvae may spread throughout the body in immunosuppressed subjects.

Department of Medicine, University of Western Australia, and the Repatriation General Hospital, Nedlands, Western Australia 6009

D I GROVE, FRACP, DTM\&H, senior lecturer

\section{Introduction}

The nematode Strongyloides stercoralis is widely distributed throughout the tropics and subtropics. Infection is acquired when worms penetrate the skin; they pass via the blood stream to the lungs, ascend the respiratory tract, are swallowed, and grow into adult worms in the mucosa of the small intestine. The organism has an unusual ability to replicate in man; consequently infection may persist for years. The importance of the infection is twofold. Firstly, it may contribute to the ill health of infected persons, although this has been difficult to document because of concurrent infections with other intestinal parasites. Secondly, an overwhelming infection with widespread dissemination of larvae may supervene should such persons become immunosuppressed. ${ }^{1}$

Strongyloidiasis has been reported in Allied ex-servicemen who were prisoners of war in south-east Asia during the second world war. ${ }^{2} 3$ I decided to assess the prevalence of strongyloidiasis in an unselected sample of such men, compare the efficacies of various diagnostic methods, and try to delineate the clinical manifestations of the infection.

\section{Subjects and methods}

Letters were sent to all 201 former members of the $2 / 4$ machine-gun battalion who were identified by their association as living in the Perth metropolitan area; 160 men $(80 \%)$ replied. Their ages ranged from 55 to 80 years, with a median of 62 . The battalion was raised in Perth, captured at the fall of Singapore in January 1942, then dispersed among other Allied prisoners of war. Its members worked on the Burma-Thailand railway in 1943, and were then scattered throughout south-east Asia and Japan.

Each respondent was interviewed. In most cases it was also possible to review the clinical records from the years immediately after the war. Faeces were examined for larvae of $S$ stercoralis by direct microscopy and culture. Faeces ( $1 \mathrm{~g}$ ) were homogenised and diluted in $50 \mathrm{ml}$ water, then $0.5 \mathrm{ml}$ aliquots were placed in Sedgewick-Rafter chambers and 10 chambers examined. Faeces $(2 \mathrm{~g})$ were smeared on moistened filter paper, placed in a slanted Petri dish containing a small volume of water, incubated at room temperature for two 